\title{
The Evaluation and Analysis of Campus Cultural Activities' Positive Effects on College Students' Mental Health
}

\author{
Shuo Zhang ${ }^{1}$, Hui $\mathrm{Lu}^{2}$, Zongzheng Chi ${ }^{2}$, Zhigang $\operatorname{Yan}^{3}$, Bin Liu ${ }^{2}$, Xiaoyu Han ${ }^{1}$, Miao Tian ${ }^{1}$ \\ ${ }^{1}$ Faculty of infrastructure Engineering, Dalian University of Technology University, Dalian, China \\ ${ }^{2}$ School of Software Technology, Dalian University of Technology University, Dalian, China \\ ${ }^{3}$ Yingkou Institute of Dalian University of Technology University, Yingkou, China
}

Email address:

zhangshuo@dlut.edu.cn (Shuo Zhang), luhui@dlut.edu.cn (Hui Lu),czz.dut@163.com (Zongzheng Chi), 15140783899@163.com (Zhigang Yan), laohubinbin@163.com (Bin Liu), 108835693@qq.com (Xiaoyu Han), 314724371@qq.com (Miao Tian)

\section{To cite this article:}

Shuo Zhang, Hui Lu, Zongzheng Chi, Zhigang Yan, Bin Liu, Xiaoyu Han, Miao Tian. The evaluation and Analysis of Campus Cultural Activities' Positive Effects on College Students' Mental Health. Science Journal of Education. Vol. 4, No. 6, 2016, pp. 186-190. doi: $10.11648 /$ j.sjedu.20160406.14

Received: October 30, 2016; Accepted: November 23, 2016; Published: December 1, 2016

\begin{abstract}
This paper uses the positive impact of campus cultural activities on the formation of College Students' healthy psychology as the breakthrough point. Starting with the students of the Faculty of Infrastructure Engineering (FIE) and the School of Physics and Optoelectronic Engineering (SPOE) of the Dalian University of Technology who have high enthusiasm in extracurricular activities, it uses the self-rating scale SCL-90 for evaluation, Studying and analyzing the differences of the mental health condition between the students with high enthusiasm and the common students. Then offer opinions and suggestions on solving the mental health problems of college students, in order to help the students to improve the psychological quality and provide information for the majority of teachers, education work and student work, then serve the students work in Colleges and universities.
\end{abstract}

Keywords: Campus Cultural Activities, Psychological Assessment, Health Status Differences

\section{Introduction}

With the continuous expansion of higher education, college students have been emerging in an endless stream of employment pressure, life stress, emotional stress, academic pressure and other problems, and mental health problems caused by gradually have become the focus of people's attention. According to the survey data from the education department, "there are $20.33 \%$ to $25.63 \%$ of the college students have different degrees of psychological problems, psychological obstacles or mental disorders, arising from which the trend of runaway, drop out, suicide and even murder is going up." Therefore, how to make college students become physical and mental health professionals has become a major problem for college teachers. [1]

College students are in an important period of the development of life, the university stage is the key period of the formation of the world outlook, life outlook and values outlook. If the psychological problems of college students cannot be resolved in a timely manner, there will be a lot of adverse effects on their healthy growth. More seriously, it will make them appear behavior disorder or personality defects. Therefore, we must strengthen the degree of attention to college students' psychological health, help them improve the psychology and personality, and training talents who can face the setbacks and challenges in today's society and are with strong psychological qualities. [2] Except for the pressure from the society, school and parents, the other cause of College Students' psychological problems is they don't have a reasonable and effective way to alleviate the pressure when faced with pressure coming from the outside.

The university campus is a colorful world. There are a lot of rich and colorful activities carried out by the student union, community, and grade team. Participating in these activities, 
students can enrich their lives, alleviate pressure of their own. And in the activity, they can subtly increase their communication skills and language ability and their own quality. It makes them more confident and has positive effects on the formation of healthy psychology.

According to this situation, this paper uses the positive impact of campus cultural activities on the formation of College Students' healthy psychology as the breakthrough point, starting research on the students of the Ministry of Construction Engineering, Physics and Optoelectronic Engineering Institute of the Dalian University of Technology who have high enthusiasm in extracurricular activities. [3] In order to help the student cadres to improve the psychological quality and inspire greater potential, and provide information for the majority of teachers, education work and student work, then serve the students work in Colleges and universities.

\section{Main Body}

\subsection{Research Objects}

The objects of this investigation mainly are the common universal science and engineering students of Dalian University of Technology, 160 students of the FIE and the SPOE who started college in 2010 were surveyed. [4] This survey divides the students into two sample groups, among which 80 students with high enthusiasm in extracurricular activities (Hereinafter would be called active molecules) formed the test group while the other students with low enthusiasm (Hereinafter would be called non-active molecules) formed the comparison group. The two sample groups are made up of 80 science and engineering students. In the selection of test objects, we selected students of different gender, different age and different faculties. The specific circumstances will be shown in Table 1 .

Table 1. The Specific Circumstances of Test Objects.

\begin{tabular}{|c|c|c|c|c|c|c|c|c|c|c|c|}
\hline \multirow{2}{*}{ Classification } & \multicolumn{2}{|c|}{ Department } & \multicolumn{2}{|c|}{ Gender } & \multicolumn{2}{|l|}{ Enthusiasm } & \multicolumn{5}{|c|}{$\overline{\text { Age }}$} \\
\hline & FIE & SPOE & Male & Female & Active Molecules & Non-Active Molecules & 18 & 19 & 80 & 21 & 22 \\
\hline Popularity & 80 & 80 & 100 & 60 & 80 & 80 & 12 & 26 & 68 & 38 & 16 \\
\hline
\end{tabular}

\subsection{Research Method}

The survey used the questionnaire survey method to test. Based on the psychological test the students filled in the mental health and counseling center of Dalian University of Technology, the high reliability and validity of the symptom self-rating scale SCL-90 has been used in this survey. [5] There are 10 factors and 90 items in this scale, including the rich content of the symptoms of mental illness like thinking, emotion, behavior, interpersonal relationships and life habits, etc., which can fully reflect the whole picture of the behavior of the tested person. There are 5 levels in this scale: No symptoms (1 point), mild symptoms ( 2 points), moderate symptoms ( 3 points), slightly severe symptoms (4 points), severe symptoms ( 5 points).

\subsection{Research Results}

Through the preliminary investigation and test, using the single factor analysis of variance to compare the motivation, gender, school and age, we came to and have compared the present psychological state of the active and non-active molecules in the Department of science and engineering of Dalian University of Technology.

\subsubsection{Comparison of Active and Non-active Molecules}

Different from the results shown in other survey, the results of this investigation compared the active molecules with the non-active molecules. It is shown that the average number of the 9 factors of SCL-90 is almost lower than that of non-active molecules, which means the psychological quality of active molecules is better than that of non-active molecules. (See Table 2)

Table 2. Description of Active and Non-active Molecules

\begin{tabular}{|c|c|c|c|c|}
\hline \multirow{2}{*}{ Subjects } & \multicolumn{2}{|c|}{ Active Molecules } & \multicolumn{2}{|c|}{ Non-active Molecules } \\
\hline & Average & Standard Deviation & Average & Standard Deviation \\
\hline Somatization & 1.068 & 0.0797 & 1.215 & 0.3997 \\
\hline Force & 1.403 & 0.3676 & 1.7 & 0.6341 \\
\hline Interpersonal Sensitivity & 1.275 & 0.3111 & 1.56 & 0.613 \\
\hline Depression & 1.188 & 0.2311 & 1.392 & 0.4779 \\
\hline Anxiety & 1.392 & 0.4779 & 1.352 & 0.4449 \\
\hline Hostile Mood & 1.175 & 0.2677 & 1.345 & 0.4212 \\
\hline Paranoid & 1.25 & 0.2562 & 1.378 & 0.4382 \\
\hline Mental Illness & 1.165 & 0.1748 & 1.239 & 0.34 \\
\hline
\end{tabular}

\subsubsection{Descriptive Statistics of Different Departments}

According to Table 3, The psychological quality of the students of SPOE is generally better than that of FIE, which is shown more obviously in two factors, "Interpersonal Sensitivity" and "Paranoid". The reason is not difficult to find out. As a larger department in DLUT, FIE contains more students. Comparing to whom of SPOE, students of FIE are faced with much more difficulties in interpersonal relationship processing and competitive pressure. In order to occupy a space for one's own, most students would try their best. That's 
why the pressure the FIE students bear is much heavier than

and paranoid problems appeared.

that the SPOE students do. Therefore, interpersonal sensitivity

Table 3. Description of Different Departments.

\begin{tabular}{lllll}
\hline \multirow{2}{*}{ Subjects } & \multicolumn{2}{l}{ Active Molecules } & \multicolumn{2}{l}{ Non-active Molecules } \\
\cline { 2 - 5 } & Average & Standard Deviation & Average & Standard Deviation \\
\hline Somatization & 1.131 & 0.375 & 1.151 & 0.1976 \\
Force & 1.428 & 0.5424 & 1.668 & 0.5096 \\
Interpersonal Sensitivity & 1.185 & 0.255 & 1.544 & 0.5661 \\
Depression & 1.188 & 0.2311 & 1.392 & 0.4779 \\
Anxiety & 1.195 & 0.3387 & 1.363 & 0.378 \\
Hostile Mood & 1.144 & 0.2703 & 1.371 & 0.4026 \\
Terror & 1.08 & 0.148 & 1.24 & 0.343 \\
Paranoid & 1.177 & 0.2767 & 1.444 & 0.3886 \\
Mental Illness & 1.149 & 0.2919 & 1.324 & 0.3632 \\
\hline
\end{tabular}

\subsubsection{Descriptive Statistics of Different Genders}

According to Table 4, comparing with the girls, boys' psychological problems is more serious. The cause can still be attributed to the environment. For the Engineering Department where the boys take the most place of the popularity, the pressure of the boys is far greater than the girls. No matter in the study, work, life and other aspects, the boys have been given a higher demand, which makes them work harder than girls. On the basis of the same bearing capacity, the boy's psychological problems must be more than girls.

Table 4. Description of Different Genders.

\begin{tabular}{|c|c|c|c|c|}
\hline Gender & Boys & & Girls & \\
\hline Subjects & Average & Standard Deviation & Average & Standard Deviation \\
\hline Somatization & 1.152 & 0.327 & 1.100 & 0.103 \\
\hline Force & 1.591 & 0.584 & 1.394 & 0.224 \\
\hline Interpersonal Sensitivity & 1.456 & 0.548 & 1.262 & 0.213 \\
\hline Depression & 1.323 & 0.417 & 1.156 & 0.183 \\
\hline Anxiety & 1.294 & 0.400 & 1.231 & 0.182 \\
\hline Hostile Mood & 1.277 & 0.392 & 1.194 & 0.191 \\
\hline Paranoid & 1.344 & 0.391 & 1.194 & 0.177 \\
\hline Mental Illness & 1.248 & 0.368 & 1.239 & 0.340 \\
\hline
\end{tabular}

\subsubsection{Descriptive Statistics of Different Ages}

According to the data, it is not hard to find that generally speaking, the older the people grow, the worse the psychological quality gets. So it would be more easier for those older people to get psychological problems. Take the 18 -year-olds and 20-year-olds as examples, the appearance is very obvious. The average of the 7 factors-somatization, force, interpersonal sensitivity, depression, anxiety, hostile mood, terror, paranoid and mental illness are above 0.4 of the 18-year-old, which are high. Through the analysis it can be found that though they are at the same grade, the age gap makes the way people think and deal with problems are more cautious and sensible for those older students. At the same time, the attitude to life the older students have is deeper and more mature. Therefore, they tend to bear more pressure and would be easier to appear psychological problems comparing with the younger students.

Among the 10 factors, terror is different from the others. The value of 18 -year-olds (1.20) is the highest. It's easier for the young to behave terror. The reason is simple. College is a place where students need self-management and self-control. For those younger students, it would be easy to scare for leaving their parents. And this feeling would decrease or even disappear with the grow of the age.

Table 5. Description of Different Ages.

\begin{tabular}{lllllll}
\hline Age & $\mathbf{1 8}$ & & $\mathbf{1 9}$ & & $\mathbf{2 0}$ & \\
\hline Subjects & Average & Standard Deviation & Average & Standard Deviation & Average & Standard Deviation \\
\hline Somatization & 1.050 & 0.071 & 1.078 & 0.109 & 1.110 & 0.135 \\
Force & 1.100 & 0.000 & 1.544 & 0.347 & 1.453 & 0.422 \\
Interpersonal Sensitivity & 1.000 & 0.000 & 1.467 & 0.427 & 1.340 & 0.295 \\
Depression & 1.200 & 0.141 & 1.167 & 0.229 & 1.243 & 0.396 \\
Anxiety & 1.050 & 0.071 & 1.189 & 0.190 & 1.207 & 0.265 \\
Hostile Mood & 1.000 & 0.000 & 1.189 & 0.232 & 1.200 & 0.327 \\
Terror & 1.200 & 0.283 & 1.090 & 0.127 & 1.150 & 0.276 \\
Paranoid & 1.000 & 0.000 & 1.222 & 0.254 & 1.250 & 0.386 \\
Mental Illness & 1.000 & 0.000 & 1.133 & 0.141 & 1.183 & 0.282 \\
\hline
\end{tabular}




\subsubsection{Descriptive Statistics of Different Ages}

According to the data, it is not hard to find that generally speaking, the older the people grow, the worse the psychological quality gets. So it would be more easier for those older people to get psychological problems. Take the 18-year-olds and 20-year-olds as examples, the appearance is very obvious. The average of the 7 factors-somatization, force, interpersonal sensitivity, depression, anxiety, hostile mood, terror, paranoid and mental illness are above 0.4 of the 18-year-old, which are high. Through the analysis it can be found that though they are at the same grade, the age gap makes the way people think and deal with problems are more cautious and sensible for those older students. At the same time, the attitude to life the older students have is deeper and more mature. Therefore, they tend to bear more pressure and would be easier to appear psychological problems comparing with the younger students.

Among the 10 factors, terror is different from the others. The value of 18 -year-olds (1.20) is the highest. It's easier for the young to behave terror. The reason is simple. College is a place where students need self-management and self-control. For those younger students, it would be easy to scare for leaving their parents. And this feeling would decrease or even disappear with the grow of the age.

Table 6. Description of Different Ages.

\begin{tabular}{|c|c|c|c|c|c|c|}
\hline Age & 18 & & 19 & & 20 & \\
\hline Subjects & Average & Standard Deviation & Average & Standard Deviation & Average & Standard Deviation \\
\hline Somatization & 1.050 & 0.071 & 1.078 & 0.109 & 1.110 & 0.135 \\
\hline Force & 1.100 & 0.000 & 1.544 & 0.347 & 1.453 & 0.422 \\
\hline Interpersonal Sensitivity & 1.000 & 0.000 & 1.467 & 0.427 & 1.340 & 0.295 \\
\hline Depression & 1.200 & 0.141 & 1.167 & 0.229 & 1.243 & 0.396 \\
\hline Anxiety & 1.050 & 0.071 & 1.189 & 0.190 & 1.207 & 0.265 \\
\hline Hostile Mood & 1.000 & 0.000 & 1.189 & 0.232 & 1.200 & 0.327 \\
\hline Paranoid & 1.000 & 0.000 & 1.222 & 0.254 & 1.250 & 0.386 \\
\hline Mental Illness & 1.000 & 0.000 & 1.133 & 0.141 & 1.183 & 0.282 \\
\hline
\end{tabular}

\section{Suggestions}

The ways of solving college students' mental problems should not be limited in mental health education and psychological consultation while they should be integrated into learning, life and work of college students. The care and training should be infiltrated into every corner of their study, life and work. [6] Ideological and political workers should pay more attention to the combination of education guidance and care services, and should combine the college students ideological and political workers' daily work closely with "people first", "humanistic care", "psychological counseling".

Through the data analysis we can see that many students participating into more extracurricular activities have better psychological health. [7] They are optimistic, cheerful, good at communication, and have the courage to face difficulties and challenges. Therefore, we should pay more attention to the role of extracurricular activities in mental health education.

\subsection{Carry Out Group Counseling Based Mental Health Activities}

The core of College Students' psychological problems lies in self-concept. College students' who have mental problems tend to consider that they are under pressures which others are not. However, through the group counseling, and the self-sharing between group members, they will realize that everybody has the same worries, by which they will reduce the psychological burden, change their improper self-evaluation, and establish a positive self-concept. What's more, in the community, the team members share their efforts to seek change and progress, which will have a certain impact on encouraging the group members, help them restore self-confidence and stimulate their potential.

This kind of group activities can also help the members to improve their communication ability, overcome the fear of communication, and promote their mental health. With the rapid development of the network and the gradual popularization of the network application, college students' communication confusion has become one of the main problems that affect the mental health of college students. In group activities, the members exchange and share with each other. Through understanding their own and other members, they can effectively master the skills to deal with interpersonal relationships, thereby improving the level of mental health.

\subsection{Actively Organize a Variety of Extracurricular Activities, and Guide a Wide Range of Students to Participate}

Abundant extracurricular activities have a good help in cultivating students' good, healthy personality, strong will and good character. A variety of extracurricular activities on the one hand can correct the unhealthy psychological tendency of college students, and cultivate good personality and psychological quality. On the other hand, they can also eliminate the psychological barrier, relieve psychological stress, depression and trouble, maintain the psychological balance, and exercise the ability to withstand the psychological. [8]

College students can increase a relaxed and happy life experience, translate the pace of life under the pressure, and learn about self-regulation and self-grooming in subtle through participating into extracurricular activities. So we should pay more attention to the importance of extracurricular 
activities in college students' psychological health education, and organically and carry out a series of beneficial activities which are good for college students' psychological growth in purpose, especially sports and arts activities.

\subsection{Carefully Organize Relevant Practice Activities and Increase Experience}

Famous educator Mr. Tao Xingzhi put forward the concept of "society is school" and "life is education", which is of high significance for our carrying out extracurricular activities to improve mental health. When students participate in practice activities, their experience is more profound. And through contact with the community they can exercise their communication and organization ability and enhance their self-confidence. Finally, they can overcome the psychological barriers and increase the level of mental health. [9]

For instance, while organizing students to collect donations for the earthquake area people, on one hand we can make the students improve their abilities in event planning, implementation and summary. On the other hand, the students' patriotic helping others would get practiced and sublimated. In the donation collection, students can eliminate the fear of strangers and improve self-confidence and psychological endurance through communicating with strangers. In the past similar activities, the participating students have said, "The stranger is not so difficult to contact", "I am very grateful to those strangers who's filled with love and kindness, there are more kind people among the strangers", and so on. With the personal feelings, these emotional resonances the students have gained from other class activities cannot be compared with those from practice activities.

\subsection{Epilogue}

For contemporary college students, they are infatuated with the Internet, have a strong personality, and like differences. So they may not soon recognize the effect of our extracurricular activities. This requires us to strengthen the quality of extracurricular activities and come up with some boutique activities the students are interested in. On the other hand, we should actively guide the students to participate in the activities, so that they can feel the interaction between people and the happiness of sharing, and gradually enhance their self-confidence, and eventually fall in love with the joy of collective life. [10]

\section{Conclusion}

Through the statistical assumptions analysis of each factor, we found that group effect (active molecules compared with non-active molecules) is significant $(\mathrm{P}<0.05)$; Gender impact is significant $(\mathrm{P}<0.05)$; Age effect is extremely significant $(\mathrm{P}$ $<0.01)$; Department difference is extremely significant $(\mathrm{P}<$ $0.01)$. It can be seen that the group effect has a significant impact, that is, the level of mental health of the active molecules is significantly better than the non-active molecules. However we can also see that the differences of the gender, age and the department can have a serious impact on the level of the students' psychological health. So while doing a good job in promoting the level of students' mental health, we should also pay attention to the guidance of the students' personality and form a work idea of the combination of macro and micro, overall and individual.

\section{Acknowledgements}

This work is funded by Liaoning Province Education Reform Project $<$ The Research and Practice of Constructing the Mechanism of Innovation and Entrepreneurship Education Throughout the Whole Process of Talent Cultivation> (2016-dlut-2-8).

\section{References}

[1] Zhou Liuzhu. Analysis of the Causes of College Students' Mental Health and Countermeasures [J], Research on Higher Education in China, 2006, 7 (2): 67 (8): 109.

[2] Fang Jiyong. Discussion on Mental Health of College Students $[\mathrm{J}]$, Science and technology information development and economy, 2005, 15 (13) 231.

[3] Zhang Zhiyong, Luo Shanhong. Comparative study on the measurement results of College Students' SCL-90 scale [J], Chinese Journal of Mental Health, 1998, (02).

[4] Wang Songmei, Zhao Xian. Discussion on SCL-90 statistics method [J], Health Soft Science, 2009, (01).

[5] Zhang Jianying. Experimental Study on Group Psychological Counseling and Mental Health of College Students [J], Journal of Anhui Science and Technology University, 2009, (01).

[6] Wang Xiuyun, Ma Junyun, Wu Baoli. School Physical Education and Mental Health of College Students - An Investigation and Analysis on the Mental Health Status of Freshmen in Beijing University of Agriculture [J], Higher Agricultural Education; 2002; (06).

[7] Kadison R, DiGeronimo T F. College of the overwhelmed: The campus mental health crisis and what to do about it $[\mathrm{M}]$. Jossey-Bass, 2004.

[8] Zivin K, Eisenberg D, Gollust S E, et al. Persistence of mental health problems and needs in a college student population $[\mathrm{J}]$. Journal of affective disorders, 2009, 117 (3): 180-185.

[9] Zivin, K., Eisenberg, D., Gollust, S. E., \& Golberstein, E. (2009). Persistence of mental health problems and needs in a college student population. Journal of affective disorders, 117 (3), 180-185.

[10] Hwang W C, Goto S. The impact of perceived racial discriminatiosn on the mental health of Asian American and Latino college students [J]. 2009. 